\title{
Analysis of Heat Release Dynamics in a Compression-Ignition Engine with Multiple Fuel Injection
}

\section{Zdzisław Chłopek, Jakub Lasocki}

Warsaw University of Technology, Faculty of Automotive and Construction Machinery Engineering, Institute of Vehicles, Department of Combustion Engines, Narbutta 84, Warsaw, 02-524, Poland, e-mails: zdzislaw.chlopek@pw.edu.pl, jakub.lasocki@pw.edu.pl

\begin{abstract}
The heat release characteristics of the combustion process in a four-stroke compression-ignition engines depend strongly on the fuel injection strategy. In the case of multiple fuel injection, deviations from the classic heat release model applicable to a single injection are observed. This paper presents the results of empirical tests and their analysis for a single-cylinder compression-ignition research engine with double injection of fuel. The influence of fuel injection pattern on the indicated pressure has been analyzed, in particular the derivative of indicated pressure in respect of the crank angle. The processes of fuel supply and heat release have been investigated in time domain. A correlation analysis of voltage controlling the opening of injector and unit heat release rate have been presented. The delay angle and delay time of unit heat-release rate in respect of the voltage controlling the opening of the injector have been determined. The heat release for each injected fuel dose has been analyzed.
\end{abstract}

Keywords: heat release; compression-ignition engine; multiple fuel injection; ignition delay

\section{Introduction}

It is widely known that fuel injection strategy plays a dominant role in determining the performance of combustion engine, especially in the case of direct-injection fuel supply systems of four-stroke compression-ignition engines $[14,15]$. Multiple or split fuel injection (i.e. the division of the fuel dose into several parts injected during one working cycle) has been applied in automotive engines for some time now. It allows a more precise control of the heat release characteristics of the combustion process and positively influences thermal efficiency of the engine as well as pollutant emission $[3,9,10,12,23]$. 
The course of the combustion process in compression-ignition engines is strongly influenced by phenomena associated with fuel injection and the formation of combustible mixture [24]. These phenomena determine the autoignition delay and the course of heat release $[2,22,25]$. They have been sufficiently investigated in the case of single fuel injection, providing analytical description that allows to generalize the formulated conclusions $[13,17]$. However, in the case of multiple fuel injection, the combustion of the second and subsequent doses of fuel proceeds differently than the first dose, for which spontaneous combustion must occur. For subsequent injections there are significant differences in the phenomena associated with ignition [16]. Firstly, mixture formation takes place under conditions other than during the first injection: at a higher temperature and higher pressure of the medium, and in an environment comprising a mixture of air, fuel vapor and exhaust components, wherein mixture formation is accompanied by already spreading flames. Secondly, the initiation of ignition occurs not only due to pre-ignition reactions, but also to flames that have already started to spread, originating from the spontaneous combustion of the first dose, and, in the case of subsequent doses, from the burning of the previous dose. There is a need, therefore, to study the dynamics of ignition delay to the subsequent fuel doses. Although there are many studies in this field, both empirical [2, 10, 22, 23, 25] and theoretical [11, 17-19, 22, 23, 25], none has so far presented generalized knowledge of the dynamics of fuel combustion processes for multiple injection.

This paper presents detailed analysis of heat release dynamics in a compressionignition engine with double fuel injection. The study was based on the results of empirical tests performed with the use of a single-cylinder compression-ignition research engine. The objective was to provide the detailed insight into the effects of splitting the fuel dose on heat release, its magnitude and rate of change.

\section{Materials and Methods}

Empirical tests that served as the basis for the considerations contained in this work have been described in the previous paper [6]. It presents the detailed technical specifications of the engine, the test stand and instrumentation, as well as characteristics of the fuel and procedures of the test program. Therefore, only basic information is given in this section.

Tests were carried out on the AVL Single Cylinder Test Bed [4] consisting of a single-cylinder compression-ignition research engine AVL 5402 (Table 1), a set of exhaust-gas analyzers, and instrumentation controlling the operation of the entire system. Data has been collected and processed using the software AVL PUMA and AVL CONCERTO. 
The test program included engine operating in static states, at the external speed characteristic with engine rotational speed within the range of 1200-3600 rpm in steps of $400 \mathrm{rpm}$. The basic measurements involved the following quantities: rotational speed $-\mathrm{n}$, torque $-\mathrm{M}_{\mathrm{e}}$, indicated pressure $-\mathrm{p}_{\mathrm{g}}$, recorded in crank angle domain $-\alpha$, voltage of the injector opening control signal $-\mathrm{U}$ as well as other quantities, which were not included in this work.

Table 1

Technical specifications of the AVL 5402 engine [6]

\begin{tabular}{|l|l|}
\hline \multicolumn{1}{|c|}{ Specification } & \multicolumn{1}{c|}{ Data } \\
\hline Number of cylinders & 1 \\
\hline Bore & $85.01 \mathrm{~mm}$ \\
\hline Stroke & $90.00 \mathrm{~mm}$ \\
\hline Displacement & $511.00 \mathrm{~cm}^{3}$ \\
\hline Combustion type & Compression ignition \\
\hline Valve system & 4 valves \\
\hline Compression ratio & $17.0 \div 17.5$ \\
\hline Fueling system & Direct injection, Common Rail \\
\hline Maximum effective power & $6 \mathrm{~kW}$ \\
\hline Rated engine speed & $4200 \mathrm{~min}^{-1}$ \\
\hline Injection pressure & $180 \mathrm{MPa}^{2}$ \\
\hline
\end{tabular}

The data on pressure inside engine cylinder was obtained by recording of 20 traces of indicated pressure vs. the crank angle at each engine working point. The measurements were performed with a resolution of $1 \mathrm{deg}$. of crank rotation, except for the crank angle in the range of -30-90 deg., corresponding to active combustion near the Top Dead Centre (TDC), where a resolution equaled $0.1 \mathrm{deg}$.

In order to reduce the contamination of recorded signals with high-frequency noise, processing of the signals was performed, consisting in synchronous averaging $[5,20]$. The rough estimator of numerical differentiation has been lowpass filtered to reduce the share of high-frequency noise in the signal [7, 8]. For filtering, a non-recurring filter was applied five times:

$\overline{y_{i}}=\frac{1}{11} \sum_{j=i-5}^{i+5} y_{j}$

where $\mathrm{y}$ - rough estimator, $\overline{\mathrm{y}}-$ filtered estimator.

The engine was supplied with diesel oil. Its properties are described in [6]. 


\section{Results and Discussion}

\subsection{Analysis of the Course of Indicated Pressure}

Figure 1 shows the influence of double fuel injection on the indicated pressure and the derivative of the indicated pressure at the engine working point corresponding to the maximum torque $(1600 \mathrm{rpm})$. In contrast, Figure 2 shows the typical curves of the indicated pressure and the derivative of the indicated pressure for the single fuel injection.

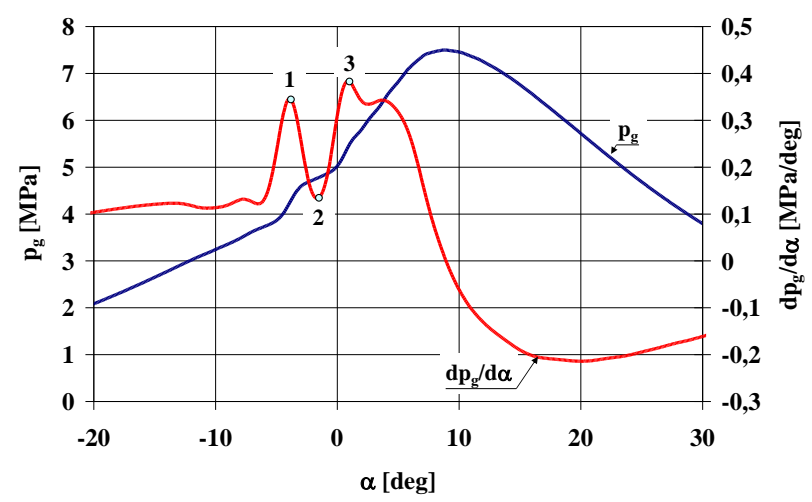

Figure 1

The indicated pressure and the derivative of the indicated pressure at the engine working point corresponding to maximum torque (1600 rpm)

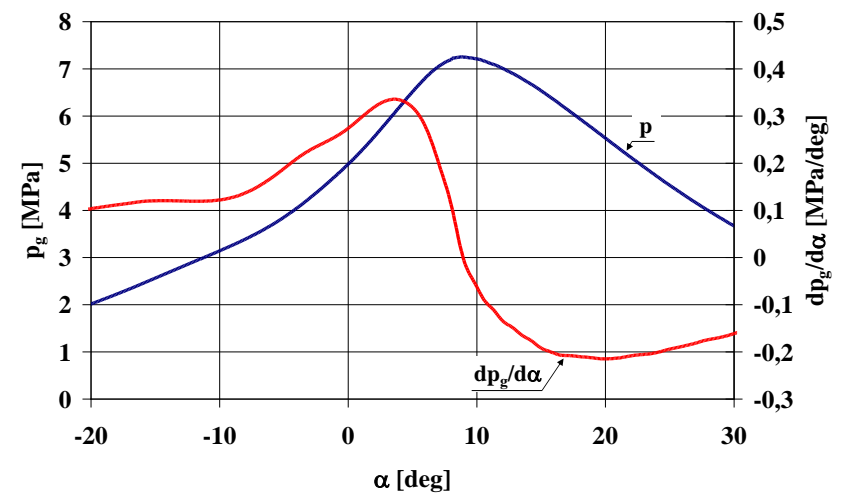

Figure 2

Typical curves of the indicated pressure and the derivative of the indicated pressure for engine with single fuel injection 
Figure 3 illustrates the relationship between the values of three extrema of the derivatives of the indicated pressure and the engine rotational speed. The average value and standard deviation of these extrema for each rotational speed are also plotted in the graph.

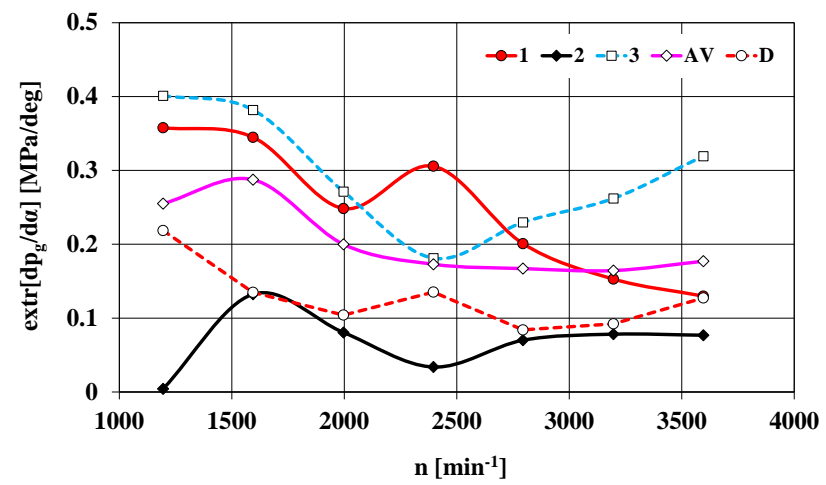

Figure 3

The values of three extrema of the derivative of the indicated pressure and their average value - AV and standard deviation $-\mathrm{D}$, depending on the engine rotational speed

\subsection{Analysis of the Processes of Fuel Supply and Heat Release}

On the basis of the indicated pressure and the information associated with the parameters of engine and fuel, the following quantities have been determined: the unit heat (understood as the heat related to the volume, i.e. the cylinder displacement), the unit heat-release rate, and the temperature of medium. For this purpose, AVL CONCERTO and AVL BOOST algorithms have been applied. Figure 4 presents the courses of those quantities along with the indicated pressure and the voltage of the injector opening control signal.

Figure 5 shows diagrams of crank angles corresponding to the important phenomena of fuel supply and heat release in the cylinder. Diagram (a) depicts the case where for the second fuel dose there is one maximum of the rate of unit heat release while diagram (b) - the case where the number of maxima is larger (three in analyzed tests). The crank angles shown in Figure 5 correspond to (notation (a) or (b) indicates that the crank angle is specific exclusively to diagram (a) or (b)): the autoignition delay - DIGN, the start of the injection control signal - US1, the maximum value of the control signal in the first injection - UMAX1, the end of the control signal in the first injection - UE1, the length of the control signal in the first injection - U1, the start of the control signal in the second injection - US2, the maximum value of the control signal in the second injection - UMAX2 (a), first maximum value of the control signal of the second injection - UMAX21 (b), 
second maximum value of the control signal of the second injection - UMAX22 (b), third maximum value of the control signal in the second injection - UMAX23 (b), average value of the maximum values of the control signal in the second injection - UMAXAV (b), the end of the control signal in the second injection $\mathrm{UE2}$, the length of the control signal in the second injection - U2, the start of the heat release in the first injection - QS1, maximum value of unit heat-release rate in the first injection - QMAX1, the start of the heat release in the second injection - QS2, the maximum value of the unit heat-release rate in the second injection QMAX2 (a), first maximum value of the unit heat-release rate in the second injection - QMAX21 (b), second maximum value of unit heat-release rate in the second injection - QMAX22 (b), third maximum value of the unit heat-release rate in the second injection - QMAX23 (b), the average value of the maximum values of the unit heat-release rate in the second injection - QMAXAV (b), the delay to the ignition of first dose - DS1, the delay to the maximum value of the unit heat-release rate in relation to the maximum value of the control signal in the first injection - DMAX1, the delay to the ignition of the second dose - DS2, the delay to the maximum value of the unit heat-release rate in relation to the maximum value of the control signal in the second injection - DMAX2 (a), the delay to the first maximum value of the unit heat-release rate in relation to the maximum value of the control signal in the first injection - DMAX21 (b), the delay to the second maximum value of the unit heat-release rate in relation to the maximum value of the control signal in the second injection - DMAX22 (b), the delay to the third maximum value of the unit heat-release rate in relation to the maximum value of the control signal in the second injection - DMAX23 (b), the average value of the maximum values of unit heat-release rate in relation to the maximum value of the control signal in the second injection - DMAX2AV (b).

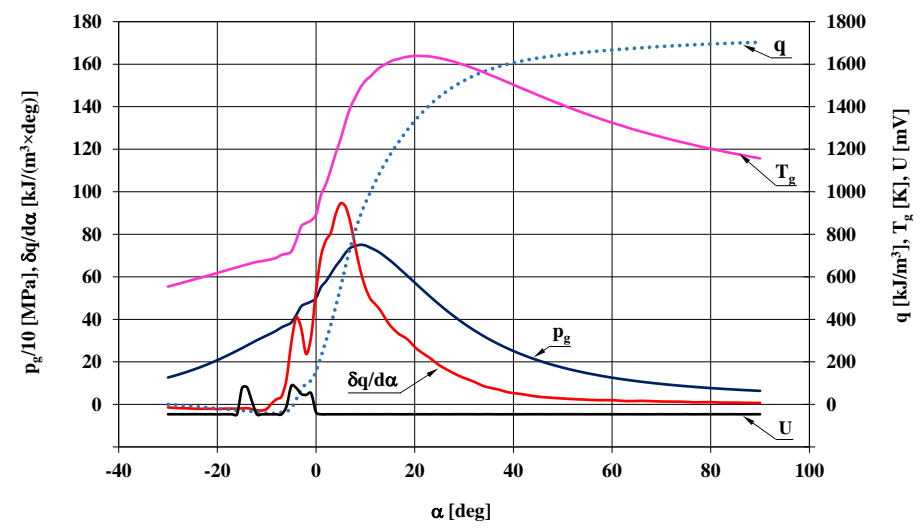

Figure 4

Indicated pressure $-\mathrm{p}_{\mathrm{g}}$, temperature of medium $-\mathrm{T}_{\mathrm{g}}$, unit heat-release rate $-\delta \mathrm{q} / \mathrm{d} \alpha$, unit heat $-\mathrm{q}$ and the voltage of the injector opening control signal $-U$ at the engine working point corresponding to maximum torque (1600 rpm) 

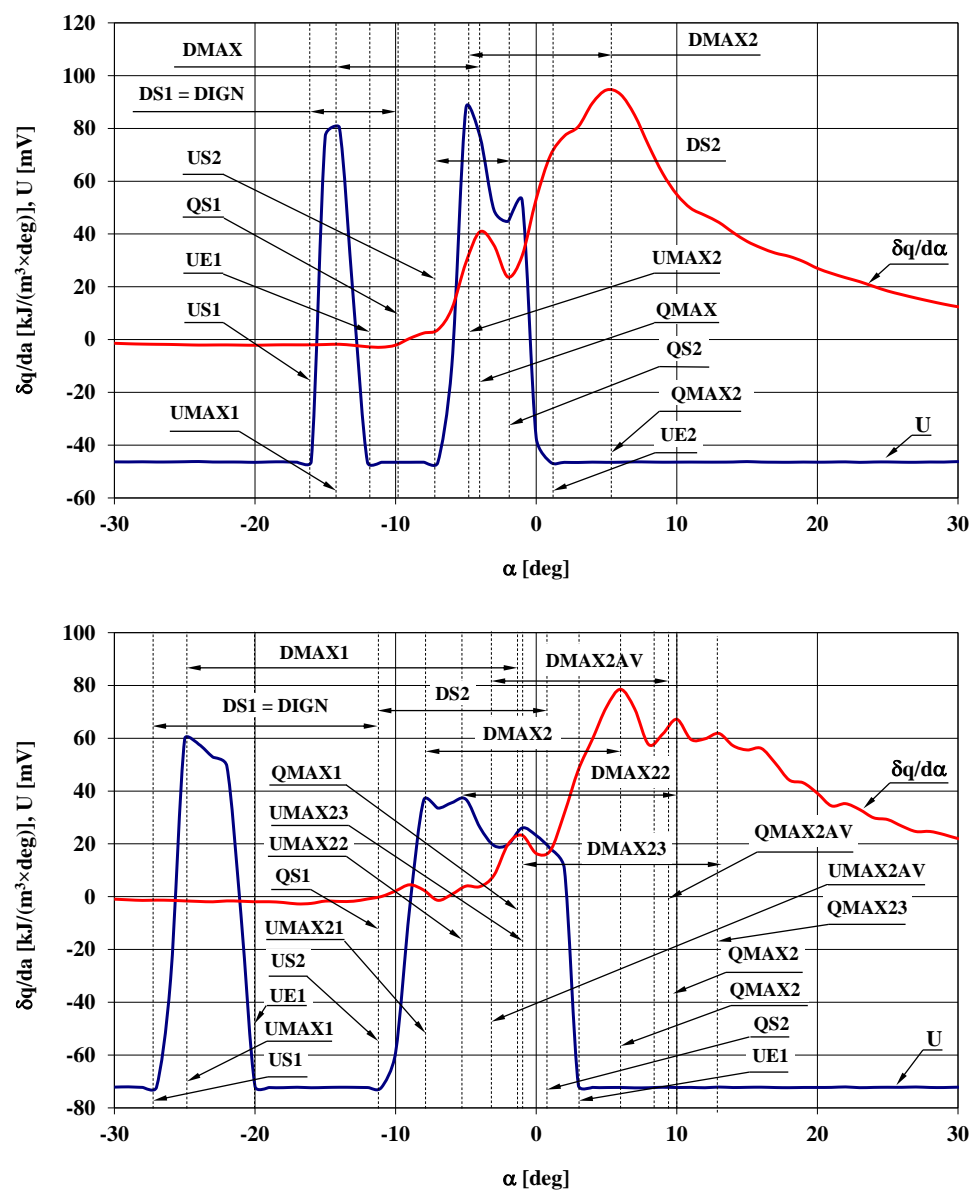

Figure 5

The rate of unit heat release $-\delta \mathrm{q} / \mathrm{d} \alpha$ and the voltage of the injector opening control signal $-\mathrm{U}$ at the engine working point corresponding to maximum torque (1600 rpm) for one maximum (a) and three maxima (b) of the rate of unit heat release (see the text for the description of the angles)

Figure 6 shows the angles corresponding to the start of injection, autoignition and autoignition delay as a dependence on the engine rotational speed. The start of the injection angle is an increasing function of the rotational speed. This is due to the fact that it is necessary to initiate combustion in the appropriate phase of the engine cycle, and for increasing the rotational speed, the shorter time corresponds to the same angle of rotation. The start of the combustion angle is practically constant in the rotational speed domain, while the autoignition-delay angle is an obviously decreasing function - approximately linearly. 
Figure 7 shows the angle of the start of the injection control signal, the angle of the maximum value of the control signal in the first injection, the angle of the end of the control signal in the first injection, and the angle of the length of the control signal in the first injection as a dependence on the engine rotational speed. The angle of the length of the control signal in the first injection is practically constant in the rotational-speed domain, while other angles decrease, which corresponds approximately to the constancy of the processes in question in the timescale.

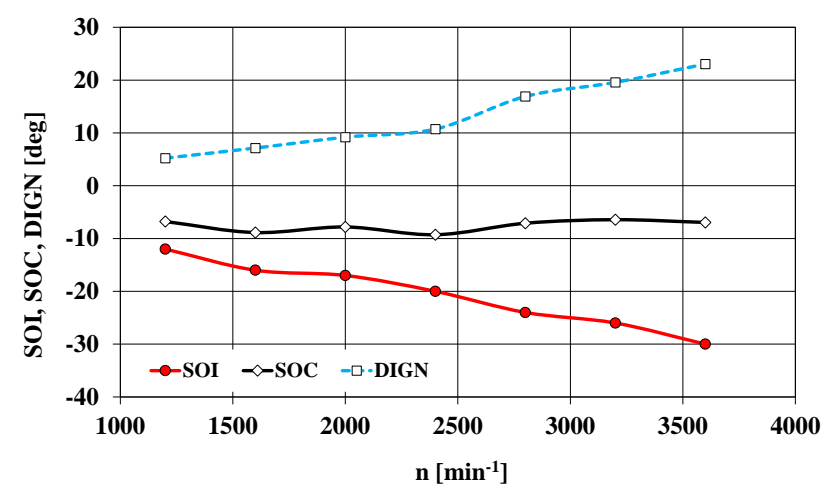

Figure 6

The start of the injection angle - SOI, the autoignition angle - SOC and the autoignition-delay angle DIGN as a dependence on the engine rotational speed

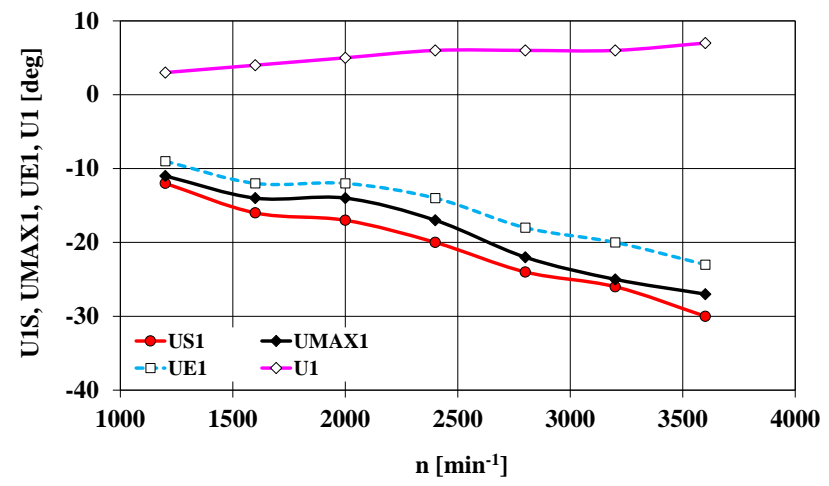

Figure 7

The angles of: the start of the injection control signal - US1, the maximum value of the control signal in the first injection - UMAX1, the end of the control signal in the first injection - UE1 and the length

of the control signal in the first injection - U1, as a dependence on the engine rotational speed

Figure 8 is an illustration of the dependence of the angles corresponding to the phenomena associated with the second injection on the engine rotational speed. It 
can be seen that the angle of the length of the control signal in the second injection increases together with the increase in the rotational speed, while injection end of the second stage is practically constant. Other angles are weakly dependent on the rotational speed with a tendency to decreasing dependence.

Figure 9 shows the relationship between the angles characterizing heat release inside engine cylinder and engine rotational speed. Analysis of the plotted data allows to evaluate this relationship as weak - no clear trend can be identified.

Figure 10 shows the relationship between the length of the control signal of subsequent injections and engine rotational speed. These are increasing functions, which corresponds to the increase of fuel dose with increasing rotational speed.

Figures 11 and 12 show the dependence of the angles of ignition delay and the maximum value of the unit heat-release rate delay in relation to the maximum value of the control signal in each phase of ignition on the engine rotational speed. These are increasing functions of the rotational speed.

Figures 13 and 14 show the relationship between the angle of the maximum value of the unit heat-release rate and the angle of the maximum value of the control signal in each phase of ignition. These are quantities weakly correlated to each other. In the first case, the Pearson linear-correlation coefficient [21] is -0.494 , and the probability that the hypothesis of the absence of a correlation would not be rejected is 0.260 , while in the second case -0.035 and 0.941 , respectively. These results can be interpreted as a lack of linear correlation between the analyzed sets.

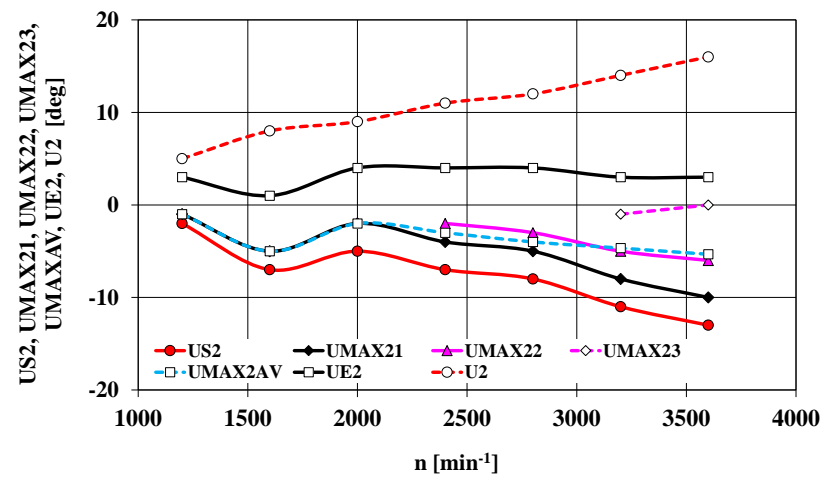

Figure 8

The angles of: the start of the control signal in the second injection - US2, the first maximum value of the control signal in the second injection - UMAX21, the second maximum value of the control signal in the second injection - UMAX22, the third maximum value of the control signal in the second injection - UMAX23, the average value of the maximum values of the control signal in the second injection - UMAXAV, the end of the control signal in the second injection - UE2 and the length of the control signal in the second injection - U2 as a dependence on the engine rotational speed 


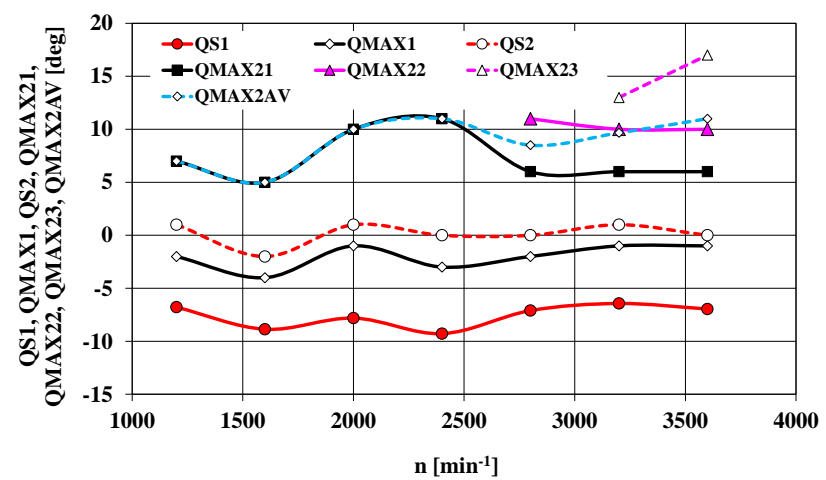

Figure 9

The angles of: the start of heat release in the first injection - QS1, the maximum value of unit heatrelease rate in the first injection - QMAX1, the start of heat release in the second injection - QS2, the first maximum value of unit heat-release rate in the second injection - QMAX21, the second maximum value of unit heat-release rate in the second injection - QMAX22, the third maximum value of unit heat-release rate in the second injection - QMAX23 and the average value of the maximum values of unit heat-release rate in the second injection - QMAXAV as a dependence on the engine rotational speed

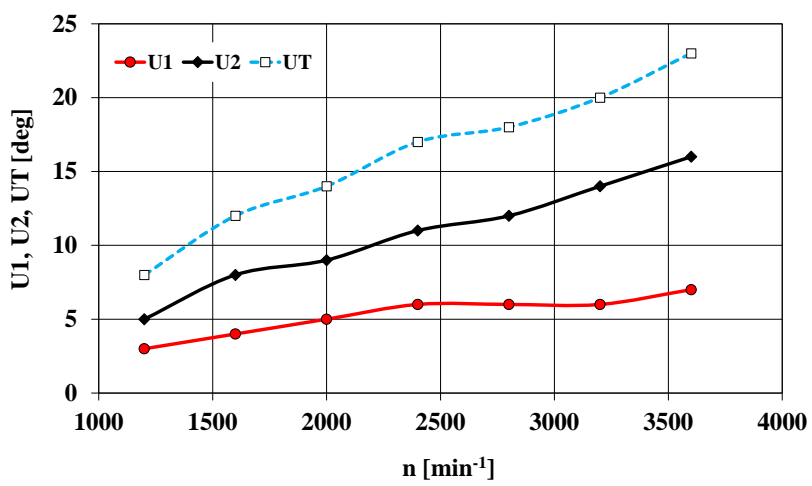

Figure 10

The angles of: the length of the control signal in the first injection - U1, the length of the control signal in the second injection - U2 and the total length of the control signal of injection - UT as a dependence on the engine rotational speed 


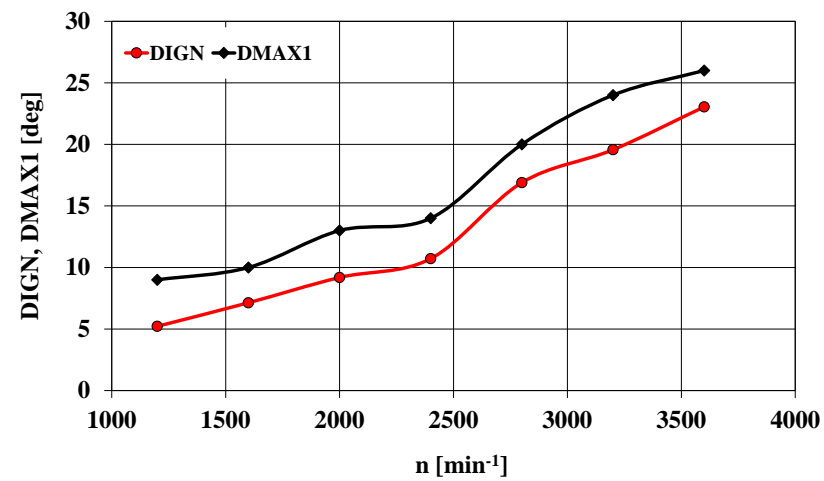

Figure 11

The angles of: the autoignition delay - DIGN and the delay to the maximum value of the unit heatrelease rate in relation to the maximum value of the control signal in the first injection - DMAX1 as a dependence on the engine rotational speed

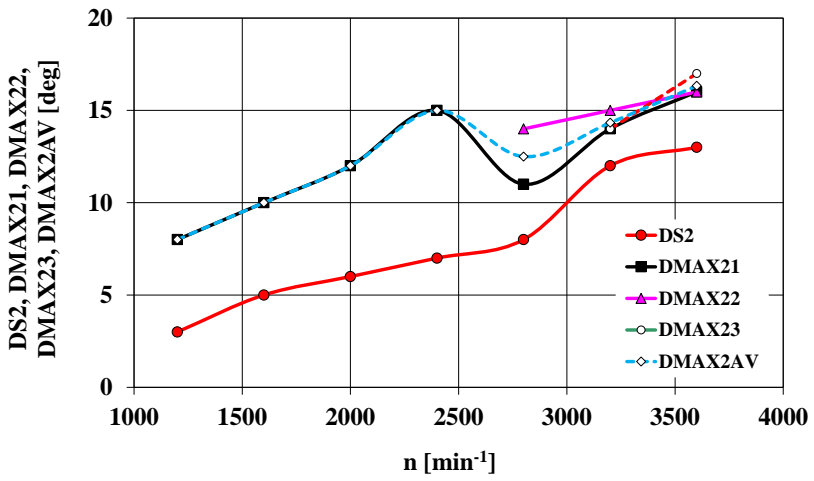

Figure 12

The angles of: the delay to the ignition of the second dose - DS2, the delay to the first maximum value of the unit heat-release rate in relation to the maximum value of the control signal in the first injection

- DMAX21, the delay to the second maximum value of unit heat-release rate in relation to the maximum value of the control signal in the second injection - DMAX22, the delay to the third maximum value of the unit heat-release rate in relation to the maximum value of the control signal in the second injection - DMAX23, the average value of the maximum values of the unit heat-release rate

in relation to the maximum value of the control signal in the second injection - DMAX2AV as a dependence on the engine rotational speed 


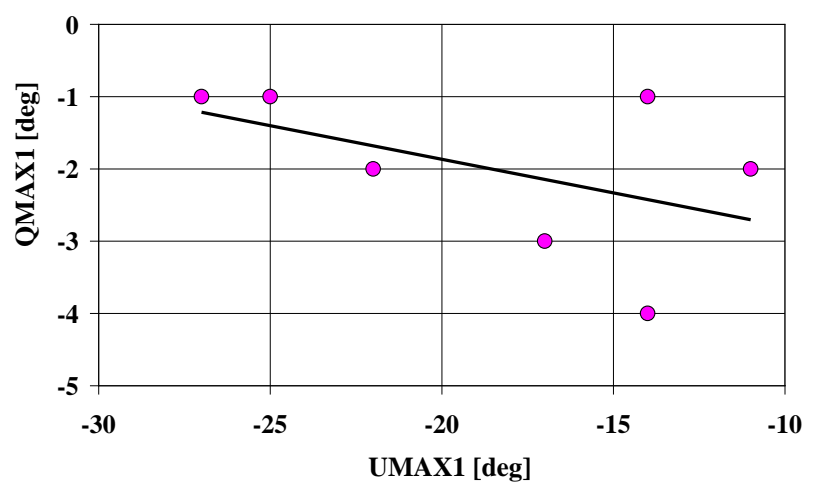

Figure 13

The relationship between the angle of the maximum value of the unit heat-release rate in the first injection - QMAX1 and the angle of the maximum value of the control signal in the first injection -

UMAX1

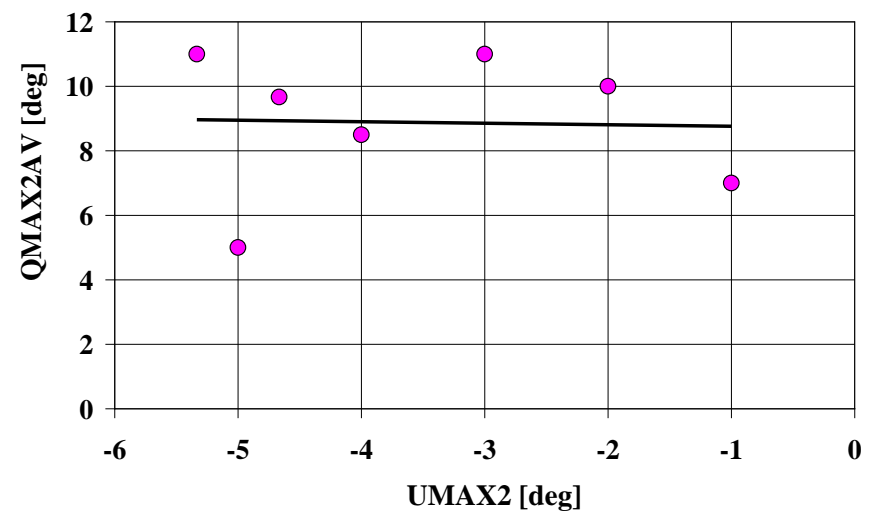

Figure 14

The relationship between the angle of the average value of maximum values of the unit heat-release rate in the second injection - QMAXAV and the angle of the average maximum values of the control signal in the second injection - UMAXAV

Since the rate of heat release is determined by the flow of fuel supplied to the cylinder, a correlation analysis of the processes of injector opening control voltage and unit heat-release rate has been performed. The algorithm using a fast Fourier transformation implemented in the Statistica 6.1 software has been used to determine the cross-correlation function of processes $[5,20]$. To investigate it, an assumption about the stationarity of these processes was adopted $[5,20]$. In this algorithm, the Fourier transform method is calculated using the mutual spectral power density of the studied processes and then the function of the cross 
correlation of these processes is determined by the method of the inverse fast Fourier transform.

Figures 15 and 16 show the cross-correlation of standardized voltage signals controlling the opening of the injector and the rate of the unit heat release in the domain of the crank angle offset for maximum torque and power output.

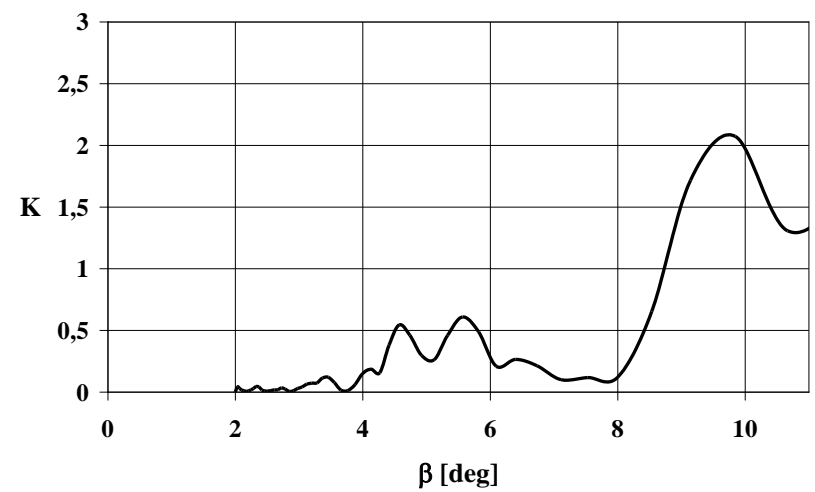

Figure 15

Cross correlation $-\mathrm{K}$ of standardized voltage signals controlling the opening of the injector $-\mathrm{U}$ and unit heat-release rate $-\delta q / d \alpha$ in the domain of the crank-angle offset $-\beta$ for maximum torque

$$
(\mathrm{n}=1600 \mathrm{rpm})
$$

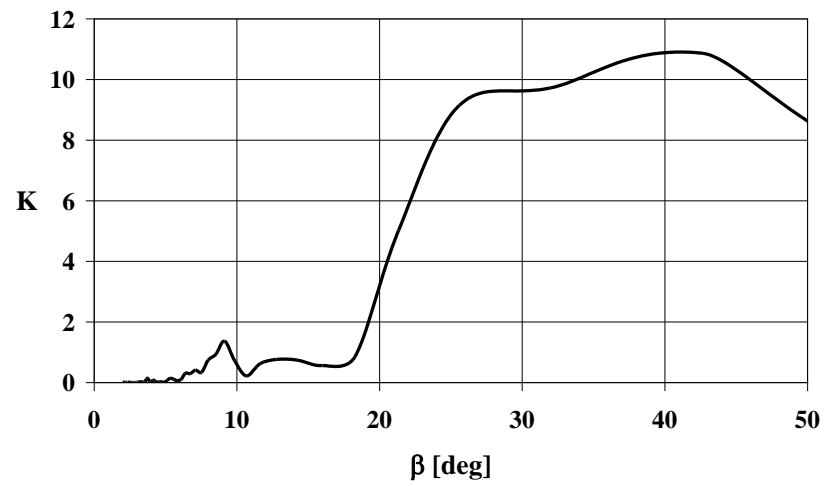

Figure 16

Cross correlation $-\mathrm{K}$ of the standardized voltage signals controlling the opening of the injector $-\mathrm{U}$ and unit heat-release rate $-\delta q / d \alpha$ in the domain of the crank-angle offset $-\beta$ for maximum power output $(\mathrm{n}=1600 \mathrm{rpm})$

The first distinct maxima correspond to the estimated delay to the signals. Figure 17 shows the speed characteristics of the delay angle and Figure 18 - of the delay 
time, for the signal of the unit heat-release rate in respect of the signal of the control voltage of the injector opening. The delay angle of the unit heat-release rate in respect of the signal of the control voltage of the injector opening is an increasing function of the rotational speed. This angle is in the range of 10-40 deg. The delay time of the unit heat-release rate in respect of the signal of the control voltage of the injector opening is weakly dependent on the rotational speed - this time depends mainly on the kinetics of the pre-ignition reactions [13, 22].

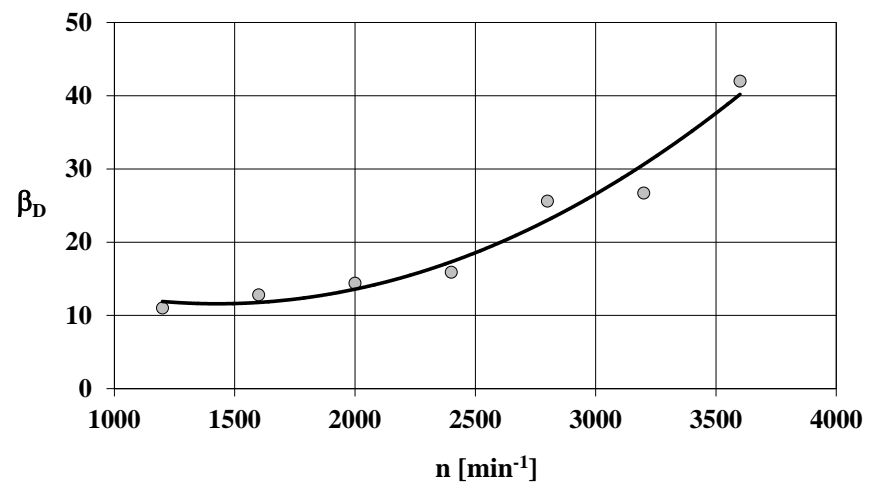

Figure 17

The speed characteristics of delay angle $-\beta_{D}$ of the signal of the unit heat-release rate in respect of the signal of the control voltage of injector opening

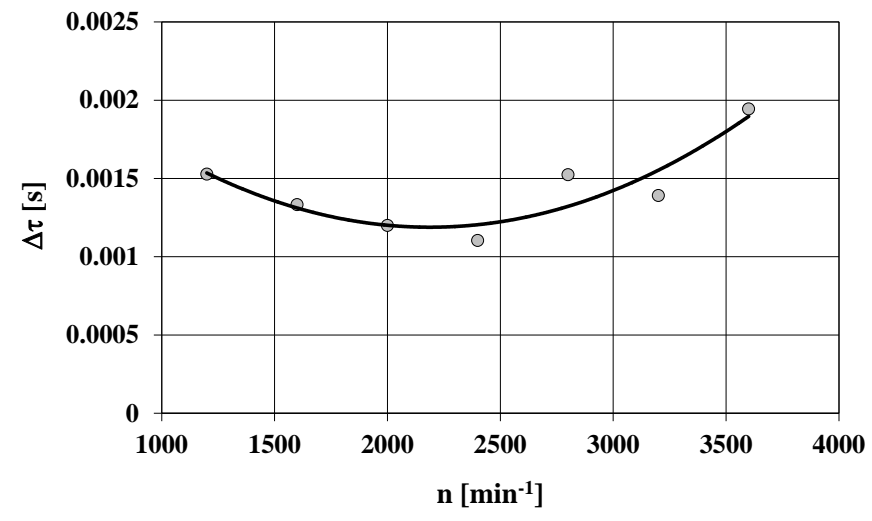

Figure 18

The speed characteristics of delay time $-\Delta \tau$ of the signal of the unit heat-release rate in respect of the signal of control voltage of injector opening 


\subsection{Analysis of the Heat Release}

The analysis of the heat release in the cylinder involved the unit heat-release rate, along with the unit heat for the two doses of the fuel injected and in various parts of the second injection, restricted by the local minima of the unit heat-release rate. Figure 19 shows schematic indications for the analysis of the heat release.

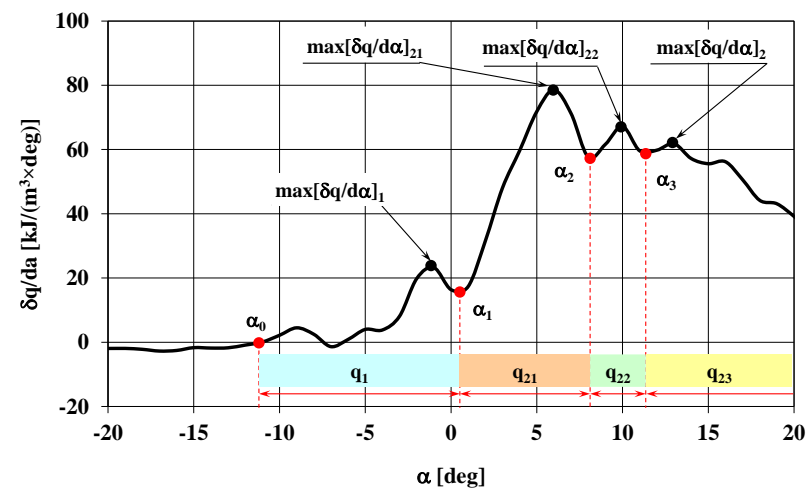

Figure 19

The unit heat-release rate - the identification of the maximum values of the unit heat-release rate and the angles limiting parts of the ith-phase of injection

The unit heat in two stages of the fuel injection and in different parts of the second injection, as well as the total unit heat $-\mathrm{q}_{\mathrm{T}}-$ were calculated according to the formulas

$$
\begin{gathered}
\mathrm{q}_{1}=\int_{\alpha_{0}}^{\alpha_{1}} \frac{\delta \mathrm{q}}{\mathrm{d} \alpha} \mathrm{d} \alpha ; \quad \mathrm{q}_{21}=\int_{\alpha_{1}}^{\alpha_{2}} \frac{\delta \mathrm{q}}{\mathrm{d} \alpha} \mathrm{d} \alpha ; \quad \mathrm{q}_{22}=\int_{\alpha_{2}}^{\alpha_{3}} \frac{\delta \mathrm{q}}{\mathrm{d} \alpha} \mathrm{d} \alpha ; \quad \mathrm{q}_{23}=\int_{\alpha_{3}}^{\alpha_{\mathrm{E}}} \frac{\delta \mathrm{q}}{\mathrm{d} \alpha} \mathrm{d} \alpha \\
\mathrm{q}_{\mathrm{T}}=\mathrm{q}_{1}+\mathrm{q}_{21}+\mathrm{q}_{22}+\mathrm{q}_{23}
\end{gathered}
$$

where $\alpha_{\mathrm{E}}-$ the angle of the conventional end of combustion.

Figure 20 shows the maximum value of the unit heat-release rate in two stages of fuel injection and in different parts of the second injection as the dependence on the engine rotational speed. The maximum unit heat-release rate in the second injection is much higher, by more than twice, than in the first injection. The maximum value of the unit heat-release rate in the first injection has a decreasing tendency in the domain of rotational speed. For the rotational speed, for which there are no more maxima of unit heat-release rates in the second injection, the maximum value of the unit heat-release rate is also a decreasing function of the rotational speed. For the higher rotational speeds the maximum value of the unit heat-release rate in the first part of the second injection increases together with the 
increase in the rotational speed, while in the subsequent parts is a decreasing function.

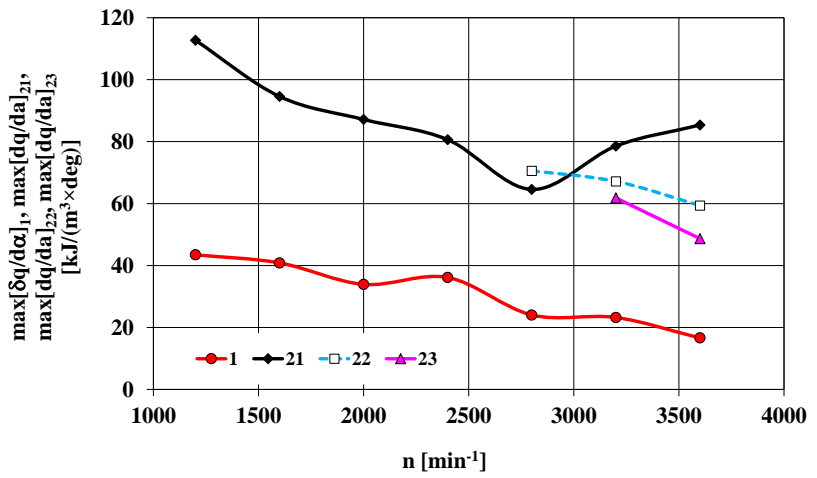

Figure 20

The maximum value of the unit heat-release rate $-\max [\delta \mathrm{q} / \mathrm{d} \alpha](1-$ in the first injection, $21-$ in the first part of the second injection, 22 - in the second part of the second injection and 23 - in the third part of the second injection) as a dependence on the engine rotational speed

Figure 21 shows the unit heat, while Figure 22 the relative unit heat, related to the total unit heat in the two stages of fuel injection and in different parts in the second injection, as a dependence on the engine rotational speed.

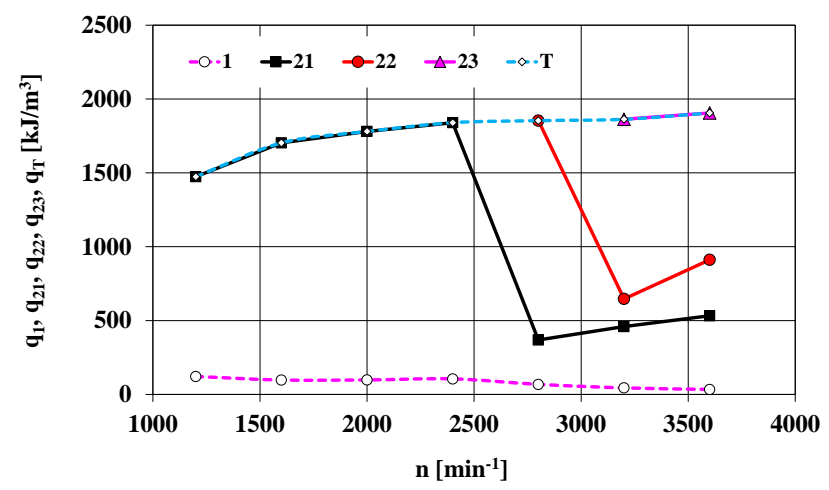

Figure 21

Unit heat $-\mathrm{q}(1-$ in the first injection, 21 - in the first part of the second injection, 22 - in the second part of the second injection, 23 - in the third part of the second injection and $\mathrm{T}$ - the total unit heat) as a dependence on the engine rotational speed 


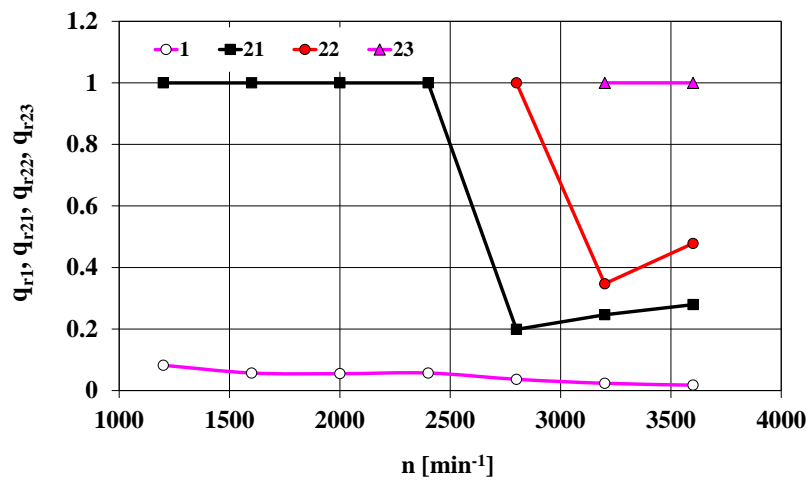

Figure 22

The relative unit heat $-\mathrm{q}_{\mathrm{r}}(1-$ in the first injection, 21 - in the first part of the second injection, 22 - in the second part of the second injection, 23 - in the third part of the second injection) as a dependence on the engine rotational speed

The unit heat being released in the first injection is almost constant over the entire useful range of rotational speed, while in the second injection the unit heat increases with the increasing rotational speed - consequently, the amount of fuel dosed by the supply system is an increasing function of the rotational speed.

\section{Conclusions}

The dynamics of the processes associated with the combustion of fuel in the cylinders of compression-ignition engines with multiple fuel injection is determined primarily by the flow rate of fuel injected into the cylinders in the individual injections. With Common Rail supply systems, the dose of fuel injected into the cylinders is primarily determined by the opening time of the injectors. It is significant to the analyzed fuel supply system that the increasing flow of fuel dosed, with increasing rotational speed, is determined mainly by the second injection, while the initiation of the combustion process is propagated by an earlier start of the injection, with increasing rotational speed.

Both the autoignition delay angle of the first fuel dose and the ignition-delay angle of the second fuel dose are increasing functions of rotational speed, which corresponds approximately to the constant value of the delay time of the autoignition and ignition of the second fuel dose. At the same time, the ignitiondelay angle of the second fuel dose is substantially smaller than the autoignition delay - this is the result of the different nature of phenomena of the combustion initiation in both cases in question.

The research work carried out proved that the angle of the maximum value of the unit heat-release rate is weakly correlated with the angle of the maximum value of the control signal in each phase of ignition, although the rate of heat release is determined by the flow of fuel supplied to the cylinder. This is confirmed by the 
results of correlation analyses of the processes of the injector-opening control voltage and unit heat-release rate. The angle of the delay to the unit heat-release rate, in respect of the signal of the control voltage of the injector opening, is approximately 10-40 deg and is an increasing function of the rotational speed. The time of delay to the unit heat-release rate, in respect of the signal of the control voltage of the injector opening, is weakly dependent on the rotational speed, as it depends mainly on the kinetics of pre-ignition reactions.

The research work carried out proved that the maximum unit heat-release rate is much higher in the second injection than in the first injection. The unit heat being released in the first injection is almost constant over the entire useful range of the rotational speed, while in the second injection the unit heat increases with increasing rotational speed.

Research into the heat release dynamics in the cylinder of compression-ignition engines with the multiple injection of fuel allows to gain knowledge about the processes occurring in engine cylinders, and - consequently - to rationally assess the impact of fuel supply on engine performance.

\section{References}

[1] Abbaszadehmosayebi, G.: Diesel Engine Heat Release Analysis by Using Newly Defined Dimensionless Parameters. PhD thesis. Brunel University, London 2014

[2] Ambrozik, A., Orliński, P., Orliński, S.: Influence of diesel engine fuelling with diferent fuels on self-ignation delay in aspect of ecology. Eksploatacja i Niezawodność - Maintenance and Reliability, 2003, 19, 50-55

[3] Atzler, F., Kastner, O., Rotondi, R., Weigand, A.: Multiple injection and rate shaping Part 1: emissions reduction in passenger car Diesel engines. SAE Technical Paper 2009-24-0004, 2009

[4] AVL: Testing solutions. Measure and control. Single-cylinder research engines \& Compact test bed. [online] Available at: https://www.avl.com//single-cylinder-research-engines-compact-test-bed [Accessed 20.02.2019]

[5] Bendat, J. S., Piersol, A. G.: Random Data: Analysis \& Measurement Procedures. Wiley, New York, 1966

[6] Chłopek, Z., Jagiełło, S., Juwa, S., Skrzek, T.: Comparative examination of performance characteristics of an IC engine fuelled with diesel oil and rape methyl esters. The Archives of Automotive Engineering - Archiwum Motoryzacji, 2016, 74, 19-32

[7] Chłopek, Z.: On selected methods of numerical differentiation on the example of cylindrical pressure course differentiation. Journal of KONES, 2001, 8, 147-153

[8] Chłopek, Z.: The subject of task explicitness in numerical differentiation. Journal of KONES, 2001, 8, 302-311 
[9] d'Ambrosio, S., Ferrari, A.: Potential of multiple injection strategies implementing the after shot and optimized with the design of experiments procedure to improve diesel engine emissions and performance. Applied Energy, 2015, 155, 933-946

[10] Di Iorio, S., Mancaruso, E., Vaglieco, B. M.: Characterization of Soot Particles Produced in a Transparent Research CR DI Diesel Engine Operating with Conventional and Advanced Combustion Strategies. Aerosol Science and Technology, 2012, 46, 272-286

[11] Gyujin, K., Moon, S., Lee, S., Min, K.: Numerical Analysis of the Combustion and Emission Characteristics of Diesel Engines with Multiple Injection Strategies Using a Modified 2-D Flamelet Model. Energies, 2017, 10(9), 1292

[12] Han, Z., Uludogan, A., Hampson, G. J., Reitz, R. D.: Mechanism of soot and NOx emission reduction using multiple-injection in a diesel engine, SAE Technical Paper 960633, 1996

[13] Heywood, J. B.: Internal Combustion Engine Fundamentals. McGraw-Hill, New York, 1989

[14] Khandal, S. V., Banapurmath, N. R., Gaitonde, V. N., Hiremath, S. S.: Paradigm shift from mechanical direct injection diesel engines to advanced injection strategies of diesel homogeneous charge compression ignition (HCCI) engines - A comprehensive review. Renewable \& Sustainable Energy Reviews, 2017, 70, 369-384

[15] Lamas, M. I., de Dios Rodríguez, J., Castro-Santos, L., Carral, L. M.: Effect of multiple injection strategies on emissions and performance in the Wärtsilä 6L 46 marine engine. A numerical approach. Journal of Cleaner Production, 2019, 206, 1-10

[16] Lim., J., Lee, S., Min, K.: Combustion modeling of split injection in HSDI diesel engines. Combustion Science \& Technology, 2010, 183, 180-201

[17] Liu, H -P., Strank, S. M., Werst, M. D., Hebner, R. E., Osara, J.: Combustion emissions modeling and testing of conventional diesel fuel. In: Proc. ASME $20104^{\text {th }}$ International Conference on Energy Sustainability. Phoenix: CEM Publications, 2010

[18] Men, Y., Haskara, I., Zhu, G.: Multi-zone reaction-based modeling of combustion for multiple-injection diesel engines. International Journal of Engine Research, 2018, 1468-0874

[19] Merker, G., Schwarz, C., Stiesch, G., Otto, F.: Simulating Combustion. Springer-Verlag, Berlin, Heidelberg, 2006

[20] Oppenheim, A. V., Schafer, R. W.: Digital Signal Processing. Pearson, New Jersey, 1975 
[21] Pearson, K.: On the Theory of Contingency and Its Relation to Association and Normal Correlation, Dulau and Co., London, 1904

[22] Rakowski, S., Eckert, P., Witt, A.: Engine Combustion. In: Merker, G., Schwarz, C., Teichmann, R. (Eds), Combustion Engines Development. Springer, Berlin, Heidelberg, 2012, Chap. 4, 119-168

[23] Reitz, R. D.: Controlling D. I. diesel engine emissions using multiple injections and EGR. Combustion Science \& Technology, 1998, 138, 257278

[24] Samoilenko, D., Prokhorenko, A., Marchenko, A.: Simulation of processes in variable geometry turbine of high speed diesel engine. In: Proceedings of the $19^{\text {th }}$ International Conference on Transport Means 2015, Kaunas, 2223.10.2015

[25] Tauzia, X., Maiboom, A., Chesse, P., Thouvenel, N.: A new phenomenological heat release model for thermodynamical simulation of modern turbocharged heavy duty diesel engines, Applied Thermal Engineering, 2006, 26, 1851-1857 